Pesq. Vet. Bras. 35(2):177-187, fevereiro 2015 DOI: 10.1590/S0100-736X2015000200015

\title{
Neoformação óssea e osteointegração de biomateriais micro e nanoestruturados em ovinos ${ }^{1}$
}

\author{
Bruna D. Costa ${ }^{2 *}$, Nelson H. Camargo ${ }^{3}$, Nilson Oleskovicz ${ }^{4}$, Aldo Gava ${ }^{4}$, Ademar L. \\ Dallabrida ${ }^{4}$, Doughlas Regalin ${ }^{2}$, Marcos P.A. Lima² e Aury N. Moraes ${ }^{4}$
}

\begin{abstract}
Costa B.D., Moraes A.N., Camargo N.H., Oleskovicz N., Gava A., Dallabrida A.L., Regalin D. \& Lima M.P.A. 2015. [Bone formation and osteointegration of micro and nanostructured biomaterial in sheep.] Neoformação óssea e osteointegração de biomateriais micro e nanoestruturados em ovinos. Pesquisa Veterinária Brasileira 35(2):177-187. Departamento de Medicina Veterinária, Centro de Ciências Agroveterinárias, Universidade do Estado de Santa Catarina, Av. Luis de Camões 2090, Conta Dinheiro, Lages, SC 88520000, Brazil. E-mail: bruna_ditzel@yahoo.com.br
\end{abstract}

Bone replacement is often required in veterinary clinics and hospitals routine, even because fractures, bone tumors or any orthopedic disease that entail in bone loss. In this sense, biomaterials capable of promoting this substitution, avoiding the use of bone grafts or transplants have been searched. The aim of this study was evaluated the osteoregenerative capacity of biomaterials in different compositions, implanted in sheep's tibia. Eight female, mongrel sheeps, 12 months old, weighting 28,5 $\pm 7,4 \mathrm{~kg}$ were obtained for this study. Three bone defects, $6 \mathrm{~mm}$ each, in both tibias, a total of six bone defects, were produced, being four of them treated with four different types of biomaterials and two with autogenous bone grafts, as a control group. The biomaterials implanted were: hydroxyapatite (HA), beta-tricalcium phosphate (TCP- $\beta$ ), hydroxyapatite/beta-tricalcium phosphate 60:40 (HA/TCP- $\beta$ 60:40) and the nanocomposite hydroxyapatite and alumina $\left(\mathrm{HA} / \mathrm{Al}_{2} \mathrm{O}_{3} 5 \%\right)$. The animals were allocated in two groups: Group $60(\mathrm{n}=04)$, in which the animals were euthanized sixty days after the implantation of the biomaterials and Group $90(\mathrm{n}=04)$, in which the animals were euthanized ninety days after the procedure. Were performed radiograph images on the preoperative period, immediate postoperative and at 30, 60 and 90 days of postoperative period, to excluded any previously disease or postoperative complications that could compromise this research. After euthanasia, the tibias were collected for macro and microscopic evaluation, which was accessed by scanning electron microscopy (SEM) and optic microscopy. The results suggest that HA, TCP- $\beta$ and HA/TCP- $\beta$ present a great osteoregenerative capacity. The last one seems to be better for a long-term outcome, due its best control in the solubilization and releasing of calcium and phosphates ions through the biological environment during bone formation. The nanocomposite $\mathrm{HA} / \mathrm{Al}_{2} \mathrm{O}_{3} 5 \%$ didn't show a good response on this study, and we suggest new researches to better evaluate the potential and applicability of this new biomaterial. We concluded that HA, TCP- $\beta$ and HA/TCP- $\beta$ 60:40 presented excellent capacity of bone repair, and could be used as bone substituts; the association HA/TCP- $\beta$ (60:40) is superior due his intermediary velocity of absortion comparing to HA and TCP- $\beta$ isolated, providing adequate supporting to the neoformed tissue; the $\mathrm{HA} / \mathrm{Al}_{2} \mathrm{O}_{3} 5 \%$ showed incompatibility,

\footnotetext{
${ }^{1}$ Recebido em 26 de junho de 2014.

Aceito para publicação em 21 de dezembro de 2014.

${ }^{2}$ Programa de Pós-Graduação em Ciência Animal, Centro de Ciências Agroveterinárias (CAV), Universidade do Estado de Santa Catarina (UDESC), Av. Luiz de Camões 2090, Conta Dinheiro, Lages, SC 88520-000, Brasil. E-mails: doughregalin@hotmail.com,marcos_paulo@hotmail.com; *Autor para correspondência: bruna_ditzel@yahoo.com.br
} 
causing rejection reaction by the host and insignificant formation of bone tissue, suggesting further research on this material.

INDEX TERMS: Biomaterial, hydroxyapatite, beta-tricalcium phosphate, sheep, bone formation.

RESUMO.- A substituição de parte do tecido ósseo se faz necessária muitas vezes na rotina cirúrgica, seja em função de fraturas, neoplasias ósseas ou enfermidades ortopédicas que acarretem em perda óssea. Neste sentido, têm se buscado biomateriais capazes de promover esta substituição, evitando o uso de enxertos ou transplantes ósseos. 0 objetivo deste trabalho foi avaliar a capacidade osteoregenerativa de biomateriais em diferentes composições, em tíbias de ovinos. Foram utilizadas oito ovelhas mestiças texel, com 12 meses de idade e peso médio de $28,5 \pm 7,4 \mathrm{~kg}$. Após adequada preparação anestésica e cirúrgica, foram produzidos três defeitos ósseos na diáfise das tíbias em sua face medial, totalizando seis defeitos de $6 \mathrm{~mm}$ cada, sendo que quatro foram preenchidos por biomateriais, e dois por fragmentos ósseos retirados do próprio animal (autocontrole). Os materiais implantados foram: hidroxiapatita (HA), tricálcio fosfato- $\beta$ (TCP- $\beta$ ), hidroxiapatita/tricálcio fosfato- $\beta$ 60/40 (HA/TCP-b 60/40) e o nanocompósito hidroxiapatita/alumina a $5 \%\left(\mathrm{HA} / \mathrm{Al}_{2} \mathrm{O}_{3}\right.$ a $\left.5 \%\right)$. Os animais foram alocados em dois grupos: Grupo 60 (n=04), em que os animais foram eutanasiados após 60 dias da colocação dos implantes e Grupo 90 (n=04), em que a eutanásia ocorreu 90 dias após a colocação dos implantes. Foram realizadas radiografias nos períodos pré-operatório, imediatamente após o procedimento e aos 30, 60 e 90 dias de pós-operatório, a fim de excluir qualquer alteração prévia ou complicação pós-operatória, capaz de comprometer o estudo. Após a eutanásia, foram coletadas as tíbias para avaliação macro e microscópica, por meio de microscopia eletrônica de varredura (MEV) e microscopia óptica. Os resultados encontrados mostraram uma boa capacidade de neoformação óssea e uma lenta absorção da HA. O TCP- $\beta$ foi rapidamente absorvido e apresentou boa capacidade osteoindutiva e osteocondutiva, sendo observada neoformação óssea no interior dos grânulos deste biomaterial. 0 composto bifásico HA/TCP- $\beta$ (60/40) apresentou o melhor resultado a longo prazo, devido ao melhor controle na solubilização e liberação dos íons cálcio e fosfatos para o meio biológico durante o processo de neoformação óssea. 0 biomaterial nanocompósito $\mathrm{HA} / \mathrm{Al}_{2} \mathrm{O}_{3}$ a $5 \%$ não apresentou resultados promissores neste estudo, e sugerem-se novas pesquisas a fim de investigar melhor o potencial e aplicabilidade deste novo biomaterial. Conclui-se que a hidroxiapatita, o tricálcio fosfato- $\beta$ e a associação HA/TCP- $\beta$ (60/40) apresentam excelente capacidade de reparação óssea, podendo ser utilizados como substitutos ósseos; a associação HA/ TCP- $\beta(60 / 40)$ é o melhor dentre os biomateriais estudados, pois apresenta velocidade de absorção intermediária em relação à HA e ao TCP- $\beta$ isolados, fornecendo ainda uma sustentação adequada ao tecido neoformado; o biomaterial $\mathrm{HA} / \mathrm{Al}_{2} \mathrm{O}_{3} 5 \%$ se mostrou incompatível, provocando reação de rejeição por parte do hospedeiro e com insignificante formação de tecido ósseo, sugerindo novas pesquisas acerca deste material.
TERMOS DE INDEXAÇÃO: Biomaterial, hidroxiapatita, tricálcio fosfato- $\beta$, ovinos, neoformação óssea.

\section{INTRODUÇÃO}

Animais com algum tipo de fratura, geralmente causadas por trauma, correspondem à grande parte da rotina clínica-cirúrgica dos hospitais veterinários, sendo que os atropelamentos consistem na etiologia mais comum destes traumas. Já os tumores ósseos primários ou metastáticos são causas comuns de fraturas causadas por enfermidades pré-existentes (Johnson 2008). Além disso, doenças ósseas degenerativas e fraturas afetam milhões de pessoas no mundo inteiro, estimando-se que até 2020, o número de pessoas acima dos 50 anos com doenças ósseas, deverá dobrar (Sturm et al. 2010).

Há algum tempo pesquisadores vêm tentando encontrar materiais com características adequadas para restauração e substituição de tecidos ósseos tanto em seres humanos, quanto em animais. Inicialmente este processo ocorreu pela utilização de materiais biológicos, como no caso de enxertos ósseos ou mesmo transplantes. Estes podem ser classificados de acordo com a origem do material enxertado como autógenos, quando o doador é o próprio receptor; alógenos, quando o doador é da mesma espécie do receptor e xenógenos, quando doador e receptor pertencem a espécies diferentes (Martinez \& Walker 1999). Autógenos são considerados mais efetivos, porém necessitam de um procedimento cirúrgico adicional, possuem viabilidade limitada e risco de morbidade na área doadora (Legeros 2002, Moore et al. 2001). Alógenos e xenógenos têm sido estudados para superar os riscos associados ao osso autógeno, mas seus usos são limitados por problemas como rejeição, sequestro ósseo e infecção, além do potencial risco de disseminação de doenças (Legeros 2002, Moore et al. 2001).

Diante destas limitações, alguns materiais biocompatíveis estão sendo pesquisados para aplicação clínica. Neste sentido, entende-se por biomaterial, toda substância ou combinação de substâncias, de origem natural ou sintética, que não sejam drogas ou fármacos, e que podem ser usadas durante qualquer período de tempo, como parte ou como todo de sistemas que tratam, aumentam ou substituem quaisquer tecidos, órgãos ou funções do corpo (Willians 1987). Com o propósito de evitar enxertos ósseos autógenos, o material deve responder a determinados requisitos, como possuir estrutura estável, rapidez na incorporação com o tecido ósseo, promover osteocondução e gerar pouca ou nenhuma complicação associada ao seu uso (Mellonig 1991). Como a matriz mineral óssea é composta por um tipo de fosfato de cálcio, vários fosfatos de cálcio têm sido pesquisados para o desenvolvimento de substitutos ósseos (Dorozhkin, 2007). Estes materiais apresentam boa habilidade osteoindutiva, ou seja, induzem a diferenciação celular de células mesenquimais indiferenciadas em linha- 
gens osteogênicas e em tecido ósseo neoformado (Hong et al. 2010).

A hidroxiapatita é fabricada para uso clínico na forma de blocos ou grânulos, porosa ou densa (Hönig et al. 1998). Grânulos porosos são estudados por serem bem tolerados pelo tecido ósseo, facilitarem a infiltração e proliferação de osteoblastos nos contornos dos grãos e em suas microporosidades, além de promoverem a proliferação de vasos sanguíneos que são essenciais ao processo reparativo (Burstein et al. 1997, Thomson et al. 1998). Embora a hidroxiapatita sintética demonstre boa osteocondutividade, sua bioabsorção é baixa e ela permanece no organismo por muito tempo após a implantação; a hipótese é de que o biomaterial implantado seja absorvido pelos tecidos adjacentes e estimule, assim, a neoformação e reparação do tecido ósseo (Kamitakahara et al. 2008, Corrêa 2013).

Diferentes autores observaram nas composições bifásicas de fosfatos de cálcio, quando aplicadas in vivo ou em meio simulado, uma deposição de cristais de apatita óssea na superfície dos grãos e microporos, o que está associado às melhores capacidades de solubilidade que estes materiais apresentam (Daculsi 1998, Chow 2009, Rabelo Neto 2009). Estes resultados mostram que a bioabsorção e a bioatividade das composições bifásicas podem ser controlados quando se altera a razão TCP- $\beta$ /HA (Kamitakahara et al. 2008, Dalmônico 2011).

Em comparação com os fosfatos de cálcio microestruturados, as biocerâmicas com micro e nanoestruturas interconectadas, oferecem melhores condições de adesão e proliferação celular, devido às suas mais altas especificidades de superfície, porosidade em micro e nanoescala e topografia de superfície mais favorável. Estas vantagens estruturais demonstram melhor bioatividade, solubilidade e biodegradabilidade destes biomateriais quando aplicados in vivo e/ou em meio simulado (Hong et al. 2010).

Neste contexto o objetivo do presente estudo foi avaliar a resposta biológica dos implantes de biomateriais granulados microporosos de hidroxiapatita e do tricálcio fosfato- $\beta$, e do nanocompósito hidroxiapatita/alumina a 5\%, implantados em tíbias de ovinos, e correlacionar o potencial da neoformação óssea entre os diferentes biomateriais utilizados.

\section{MATERIAL E MÉTODOS}

Estudo aprovado pelo Comitê de Ética e de Bem Estar Animal CETEA da Universidade do Estado de Santa Catarina, segundo protocolo no. 1.29.12.

Foram utilizadas oito ovelhas mestiças texel, hígidas, com peso médio de $28,5 \pm 7,4 \mathrm{~kg}$ e 12 meses de idade. Previamente à inclusão no estudo, todos os animais foram submetidos à avaliação clínica, radiográfica e laboratorial (hemograma, função renal [ureia e creatinina] e função hepática [aspartato aminotransferase, fosfatase alcalina, proteína sérica total, albumina, globulinas]). Os animais selecionados foram alocados em baias para um período de adaptação de 15 dias, recebendo medicação antiparasitária, alimentação à base de ração para ovinos e silagem de milho e água ad libitum.

No dia precedente ao procedimento cirúrgico, foi realizada tosquia dos animais, tricotomia completa dos membros pélvicos e subsequente limpeza com água e iodopovidine degermante. Os mesmos foram mantidos em jejum sólido por 24 horas e hídrico de 8 horas, previamente ao procedimento cirúrgico.

No dia do estudo, os animais receberam na medicação pré-anestésica 0,3mg/kg de morfina (Dimorf ${ }^{\circledR}$. Cristália, Itapira/SP, Brasil) pela via IM e 10 minutos após $10 \mu \mathrm{g} / \mathrm{kg}$ de detomidina (Detomidin $^{\circledR}$, Syntec, Cotia/SP, Brasil) pela via IV. Decorridos 15 minutos, foram submetidos à cateterização da veia cefálica para administração de diazepam $0,5 \mathrm{mg} / \mathrm{kg}$ (Compaz ${ }^{\circledR}$, Cristália, Itapira/ SP, Brasil) e cetamina $5 \mathrm{mg} / \mathrm{kg}$ (Cetamin ${ }^{\circledR}$, Syntec, Cotia/SP, Brasil). Após a indução anestésica, foi realizada intubação com sonda endotraqueal tipo Murphy e a manutenção anestésica foi realizada com isofluorano (Isoforine ${ }^{\circledR}$, Cristália, Itapira/SP. Brasil) diluído em oxigênio a $100 \%$, a uma taxa de $50 \mathrm{ml} / \mathrm{kg} / \mathrm{min}$, em um sistema de reinalação parcial de gases. Foi realizada anestesia subaracnoide com a associação de $0,5 \mathrm{mg} / \mathrm{Kg}$ de levobupivacaína (Novabupi ${ }^{\circledR}$, Cristália, Itapira/SP, Brasil) sem vasoconstritor e 1,25mg/ $\mathrm{kg}$ de cetamina, completando-se para atingir um volume final de $1 \mathrm{~mL} / 7,5 \mathrm{~kg}$ com solução fisiológica 0,9\%. Após administração subaracnoide os animais foram mantidos em decúbito ventral por 30 minutos, para aguardar o tempo de latência dos fármacos administrados. Nesse momento os membros foram preparados para a intervenção cirúrgica asséptica.

0 procedimento cirúrgico foi realizado sempre pelo mesmo cirurgião e auxiliar. Com o animal em decúbito dorsal e o membro pélvico esquerdo preso à mesa cirúrgica, realizou-se antissepsia do membro pélvico direito em todas as suas faces. A extremidade distal do membro foi protegida por compressa estéril, enrolada e fixada ao membro por tiras de gaze. Os panos de campo foram posicionados de forma a expor a região da tíbia, desde a articulação femorotibiopatelar até a extremidade distal do membro. 0 mesmo procedimento foi realizado para acessar a tíbia do membro pélvico esquerdo.

0 acesso à tíbia foi realizado conforme técnica descrita por Piermatei \& Johnson (2004). Uma vez exposta a sua face medial, foram produzidos três defeitos ósseos, na face cortical medial (Fig.1). Dois destes defeitos foram produzidos com auxilio de uma broca odontológica de $6 \mathrm{~mm}$ (Neodent ${ }^{\circledR}$, Curitiba/PR, Brasil) os quais foram preenchidos por biomateriais. Os defeitos produzidos para estudo controle, foram fabricados com auxílio de uma trefina de $6 \mathrm{~mm}\left(\right.$ Neodent $^{\circledR}$, Curitiba/PR, Brasil), a fim de possibilitar a remoção do fragmento ósseo a ser reimplantado. 0 autoenxerto foi implantado na posição central da diáfise. Os defeitos produzidos apresentaram área padronizada e distância entre si

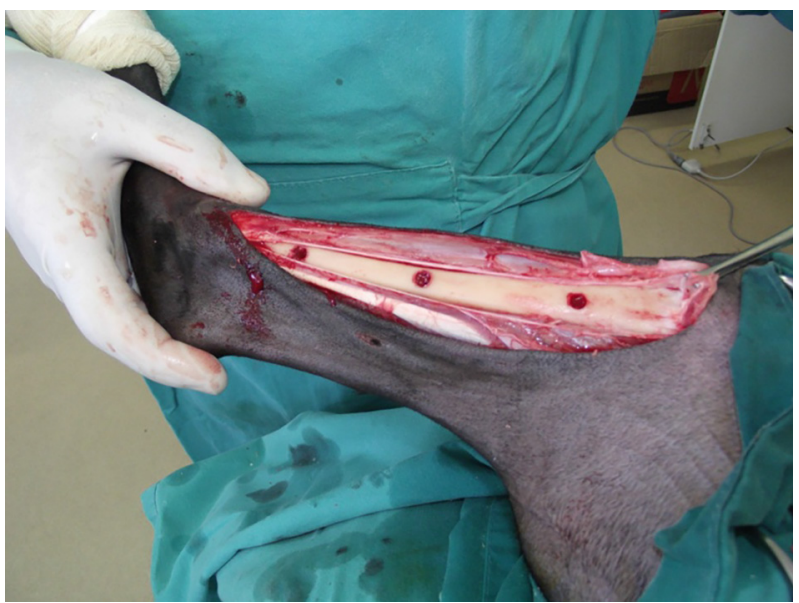

Fig.1. Tíbia direita de ovino após confecção dos defeitos em sua face medial para posterior preenchimento com os biomateriais correspondentes (proximal e distal) ou com o fragmento ósseo autógeno (defeito médio). 
de dois centímetros. Durante a realização dos defeitos, o local de perfuração foi constantemente irrigado com solução salina estéril resfriada.

Os defeitos produzidos tiveram o seu leito preenchido com quatro diferentes biomateriais: hidroxiapatita (HA), tricálcio fosfato- $\beta$ (TCP- $\beta$ ), hidroxiapatita/tricálcio fosfato- $\beta$ 60/40 (HA/ TCP- $\beta 60 / 40$ ) e o nanocompósito hidroxiapatita/alumina $5 \%$ ( $\mathrm{HA} / \mathrm{Al}_{2} \mathrm{O}_{3} 5 \%$ ), sendo cada ponto de defeito previamente identificado para o material correspondente; os dois defeitos centrais foram preenchidos pelos fragmentos ósseos, correspondendo ao grupo controle. A ordem para implantação sempre foi a seguinte: defeito proximal, defeito distal e, por último, defeito central (autoenxerto). Para a adequada aplicação dos biomateriais em seus respectivos defeitos, o biomaterial granulado foi hidratado em sangue, dando origem a uma massa viscosa (Fig.2), que facilitou o completo preenchimento dos defeitos ósseos.

A reaproximação dos planos anatômicos foi realizada mediante sutura do periósteo com fio de náilon $n^{0} 0$ (Shalon ${ }^{\circledR}$, São Luis de Montes Belos/GO, Brasil) em padrão contínuo simples. 0 fechamento da camada muscular e a redução do tecido subcutâneo foram realizados em padrão contínuo simples com fio de náilon 2-0 (Shalon ${ }^{\circledR}$, São Luis de Montes Belos/GO, Brasil). Na dermorrafia foi utilizado o mesmo fio e o padrão foi isolado simples.

Terminado o procedimento cirúrgico, foi aguardada a recuperação dos animais. Após a extubação e ainda levemente sedados, foram encaminhados ao setor de radiologia para obtenção das radiografias de controle pós-operatório imediato. Em seguida, os animais receberam bandagens de Robert-Jones modificada, associadas a canaletas de alumínio, em ambos os membros pélvicos, a fim de minimizar o risco de fraturas ou lesões aos membros operados. Estas talas foram mantidas durante 30 dias e só foram refeitas em casos específicos, como em caso de afrouxamento, desgaste ou, quando estivesse, de alguma forma, causando algum tipo de lesão ou desconforto ao animal.

No pós-operatório imediato foi mantida analgesia com 5mg/ kg de tramadol (Tramadon ${ }^{\circledR}$, Cristália, Itapira - SP - Brasil) por via subcutânea, a cada 8 horas, $25 \mathrm{mg} / \mathrm{kg}$ de dipirona $\left(F^{2} b r a x^{\circledR}\right.$, Lema-injex biologic, Vespasiano/MG, Brasil) por via subcutânea, a cada 8 horas, e $0,4 \mathrm{mg} / \mathrm{kg}$ de meloxicam (Maxicam ${ }^{\circledR} 2 \%$, Ouro Fino, Cravinhos/SP, Brasil) a cada 24 horas, durante três dias consecutivos. Foi realizada também profilaxia antimicrobiana com aplicação de $15000 \mathrm{UI} / \mathrm{kg}$ de penicilina benzatina (Pentabiótico ${ }^{\circledR}$ Veterinário, Fort Dodge, Campinas - SP - Brasil) antes da recolocação dos animais nas baias.

Foram realizadas imagens controle no período pré-operatório, imediatamente após o procedimento e aos 30,60 e 90 dias após a intervenção cirúrgica. As radiografias pré-operatórias tiveram o objetivo de descartar qualquer animal que apresentasse afecções ortopédicas que pudessem comprometer a pesquisa. No período pós-operatório, as radiografias serviram como controle, a fim de verificar a ocorrência de fraturas, fissuras ou qualquer comprometimento que pudesse descartar o animal ao longo do estudo. Para estes exames os ovinos foram mantidos em jejum sólido e hídrico a partir da noite anterior, a fim de possibilitar o uso de um protocolo sedativo leve, evitando o estresse dos animais e facilitando o posicionamento adequado para a realização das radiografias. 0 protocolo utilizado foi $0,05 \mathrm{mg} / \mathrm{kg}$ de xilazina (Xilazin $^{\circledR}$, Syntec, Cotia/SP, Brasil), pela via intramuscular.

Neste momento, os animais foram alocados em dois grupos, de acordo com o momento em que foram eutanasiados: quatro aos 60 dias de pós-operatório e quatro aos 90 dias de pós-operatório. A eutanásia foi realizada conforme Resolução CFMV nำ1000/2012, de 11 de maio de 2012. Após a coleta de ambas as tíbias, os implantes foram acessados por meio da incisão criada na intervenção cirúrgica anterior. Os ossos obtidos foram adequadamente identificados e avaliados quanto ao aspecto macroscópico e acondicionados em frascos contendo formol 10\%.

Concluída esta etapa, o osso foi dividido em três fragmentos liberando cada região implantada para análise individual. Cada fragmento obtido foi, ainda, dividido em dois, sendo que uma porção foi encaminhada à análise por microscopia eletrônica de varredura (MEV) e a outra para análise histológica por microscopia óptica.

Os fragmentos ósseos separados individualmente foram preservados em formaldeído tamponado a $10 \%$.

Foram encaminhados fragmentos de tecido ósseo cortical, em frascos identificados com a numeração referente a cada defeito produzido, biomaterial implantado, número de identificação do animal e grupo ao qual pertencia.

Após descalcificação em ácido nítrico a 10\%, as amostras foram processadas em histotécnico onde foram desidratadas em álcool, diafanizadas em xilol para serem incluídas em blocos de parafina. Posteriormente, as amostras foram seccionadas no micrótomo em cortes de 4-5 $\mu \mathrm{m}$ de espessura e coradas pelo método de hematoxilina e eosina (HE) descrito por Prophet et al. (1992), para observação em microscopia óptica. A interpretação das análises histológicas foi realizada mediante seleção de critérios adaptados de Valiati (2011). Os critérios analisados foram: neoformação de tecido ósseo, deposição de fibras colágenas, preenchimento das lacunas osteocíticas, presença de osteoblastos, formação de tecido mieloide e presença de infiltrado inflamatório, sendo, para cada critério, atribuído um número de cruzes correspondente à proporção observada.

Os estudos de caracterização morfológica e microestrutural foram realizados pelo método de microscopia eletrônica de varredura (MEV). As amostras conservadas em formol a $10 \%$ foram

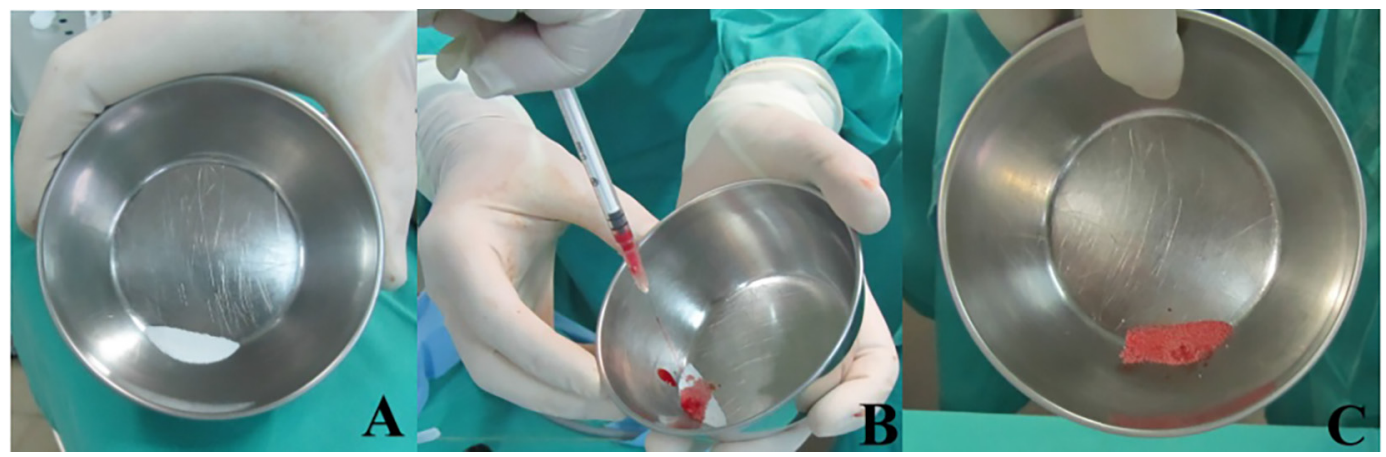

Fig.2. Preparo dos biomateriais para deposição no defeito correspondente. (A) Biomaterial liofilizado derramado em cuba estéril. (B) Gotas de sangue para hidratação do biomaterial. (C) Mistura viscosa pronta para aplicação. 
submetidas a um rigoroso processo de desidratação em álcool $70 \%$ e $100 \%$, que perdurou aproximadamente cinco dias. Após, passaram por um processo de diafanização em xilol durante um período que variava de 8-24 horas, conforme a espessura da amostra em questão, e então, retornavam para o álcool 100\% por mais 24 horas. Após esta etapa preparatória inicial, com o auxílio de um disco de diamante acoplado a um motor de alta rotação, fez-se uma pequena fissura na amostra, a fim de desenvolver um ponto de fragilidade, que permitisse a fratura do material a ser analisado.

Para facilitar os trabalhos de caracterização por MEV, as amostras foram preparadas utilizando-se um porta amostra na forma de disco em liga de alumínio com superfície lisa, onde uma fita de carbono dupla face foi fixada para a deposição do fragmento da amostra fraturada. Esta amostra foi, então, alocada em um metalizador (Bal-Tec ${ }^{\circledR}$ Sputter Coater SCD 050) e submetida ao processo de metalização por pulverização catódica, com deposição de um filme de ouro sobre a superfície da amostra a ser analisada. Os parâmetros de deposição iônica estabelecidos foram os seguintes: temperatura na câmara de metalização de $25^{\circ} \mathrm{C}$, corrente de $40 \mathrm{~mA}$, tensão de $2 \mathrm{kV}$ e tempo de deposição de 140 segundos, fornecendo um filme de ouro na superfície das partículas da ordem de $30 \mathrm{~nm}$.

Os estudos foram realizados com auxílio de microscópio eletrônico de varredura (Zeiss ${ }^{\circledR}$ DSM 940A), pelo método de elétrons secundários (SE) e retro-espelhados (BSE), com distância de trabalho entre 15 e $10 \mathrm{~mm}$ e tensão de aceleração dos elétrons de $20 \mathrm{kV}$. A análise descritiva morfológica foi realizada pelo método visual da interface entre o biomaterial implantado e a área receptora, bem como pela exploração do material remanescente e pesquisa por linhagens de células osteogênicas que se depositaram entre os grânulos do biomaterial, promovendo a formação de tecido ósseo na região do implante.

\section{RESULTADOS}

No período pós-operatório, nenhum animal apresentou complicações como infecção, deiscência de sutura ou fraturas. As análises radiológicas efetuadas demonstraram um processo de cicatrização normal, sem reação periosteal excessiva e com absorção gradativa dos biomateriais implantados. Nenhum animal apresentou fraturas ou fissuras nas regiões implantadas, não sendo necessário o descarte de nenhum ovino deste estudo.

Após a eutanásia, as tíbias foram coletadas e, macroscopicamente, a única alteração observada foi a não absorção do biomaterial $\mathrm{HA} / \mathrm{Al}_{2} \mathrm{O}_{3}$ a $5 \%$. Nas demais regiões implantadas, após 60 dias, a identificação exata da localização do defeito preenchido foi difícil, tornando-se ainda mais complexa aos 90 dias, quando praticamente não se identificava o local de implantação e não se observavam resquícios do biomaterial implantado.

A neoformação de tecido ósseo se tornou evidente com o método de microscopia eletrônica de varredura. Os resultados obtidos demonstraram uma variada morfologia dos grânulos nos diferentes biomateriais, além da presença de células de linhagens osteogênicas e fagocitárias, conforme o grupo analisado. As análises histológicas demonstraram, pela observação de critérios como o preenchimento de lacunas osteocíticas, formação de tecido mieloide e presença de osteoclastos, a qualidade do tecido ósseo neoformado nos diferentes implantes, que variou de excelente, como no caso do composto bifásico, a inexistente, como no nanocompósito $\mathrm{HA} / \mathrm{Al}_{2} \mathrm{O}_{3}$ a $5 \%$ (Quadros 1 e 2). As diferenças entre a solubilidade dos biomateriais também se tornou evidente por este método.

A hidroxiapatita apresentou boa osteointegração e boa qualidade de tecido ósseo formado, embora ainda pudesse ser notada a presença de uma quantidade significativa de biomaterial aos 60 dias. Inspecionando-se o interior dos grânulos de biomaterial remanescente, foi possível observar uma leve alteração em sua morfologia, sugerindo infiltrado celular, deposição de proteínas e mineralização da superfície do material, em relação ao seu aspecto antes da implantação no tecido vivo (Fig. 3). Aos 90 dias observou-se uma melhor osteointegração e melhor qualidade de tecido ósseo formado do que o observado aos 60 dias. No interior do grânulo, observa-se uma alteração mais marcante na morfologia do biomaterial, indicando presença mais abundante de prolongamentos celulares, deposição de proteínas e mineralização de superfície. Foi observada presença abundante de células de osteoblastos, indicando intensa proliferação de tecido ósseo, além de boa qualidade de interface entre o biomaterial e o tecido ósseo formado ao seu redor (Fig. 4). Foi observada presença de biomaterial remanescente, embora em menor proporção do que aos 60 dias.

Os resultados obtidos com o tricálcio fosfato - $\beta$ demonstraram boa osteointegração e formação óssea, inclusive no interior do grânulo (Fig. 5). Demonstrou rápida absorção e a alteração na morfologia granular foi intensa. Aos 90 dias foi observado tecido ósseo de boa qualidade preenchendo praticamente todo o defeito, com presença de pouco biomaterial remanescente. Foi observada também a presença marcante de células de linhagem osteoblástica nas superfícies do tecido ósseo em construção. Por meio da análise visual das avaliações de microscopia eletrônica e

Quadro 1. Resultados médios obtidos quanto à neoformação de tecido ósseo (NTO), deposição de fibras colágenas (DFC), preenchimento das lacunas osteocíticas (PLO), presença de osteoclastos (PO), formação de tecido mieloide (FTM) e infiltrado inflamatório (INI), dos biomateriais implantados após 60 dias

\begin{tabular}{lcccccc}
\hline & NTO & DFC & PLO & PO & FTM & INI \\
\hline HA & ++ & 0 & ++ & + & + & 0 \\
TCP- $\beta$ & +++ & 0 & +++ & + & + & 0 \\
HA/TCP- $\beta$ & ++ & 0 & ++ & + & ++ & 0 \\
HA/Al $\mathrm{O}_{3}$ & 0 & ++ & 0 & ++ & 0 & + \\
Controle & +++ & 0 & +++ & ++ & ++ & 0
\end{tabular}

Quadro 2. Resultados médios obtidos quanto à neoformação de tecido ósseo (NTO), deposição de fibras colágenas (DFC), preenchimento das lacunas osteocíticas (PLO), presença de osteoclastos (PO), formação de tecido mieloide (FTM) e infiltrado inflamatório (INI), dos biomateriais implantados após 90 dias

\begin{tabular}{lcccccc}
\hline & NTO & DFC & PLO & PO & FTM & INI \\
\hline $\mathrm{HA}$ & +++ & 0 & +++ & ++ & ++ & 0 \\
TCP $-\beta$ & ++++ & + & +++ & ++ & + & 0 \\
$\mathrm{HA} / \mathrm{TCP}-\beta$ & +++ & 0 & +++ & +++ & +++ & 0 \\
$\mathrm{HA} / \mathrm{Al}_{2} \mathrm{O}_{3}$ & 0 & +++ & 0 & ++ & 0 & +++ \\
Controle & ++++ & 0 & +++ & ++ & +++ & 0
\end{tabular}




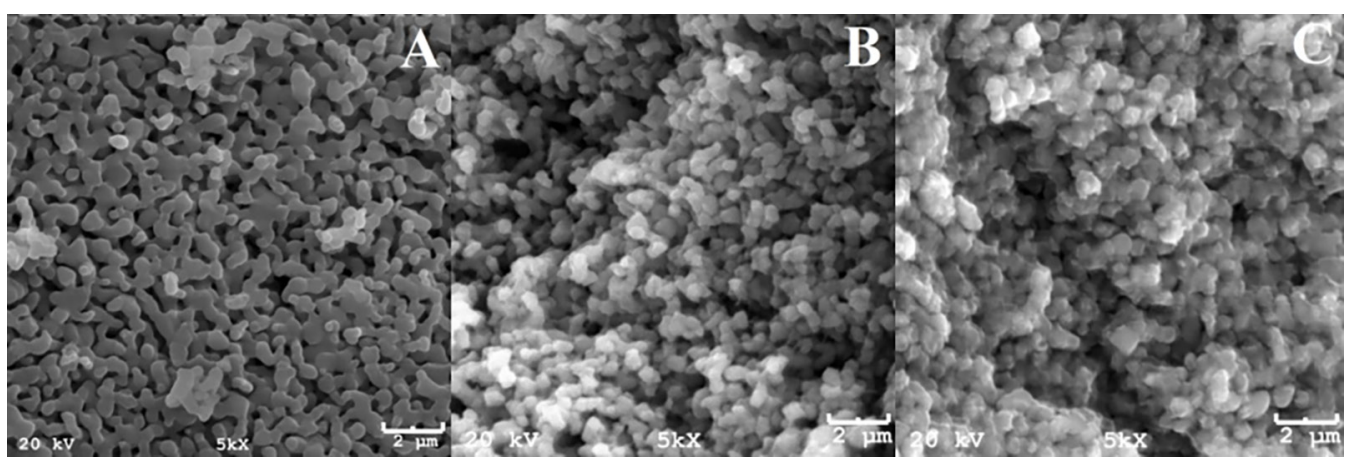

Fig.3. (A) Aspecto da micrografia dos grânulos de HA previamente à deposição no defeito ósseo. Observar a alta porosidade do grânulo. Aumento de 5000x. (B) Aspecto intragranular da HA após 60 dias da aplicação no defeito ósseo proximal da tíbia direita de ovino. Observar alteração na morfologia, com perda das limitações de poros e vilosidades. Aumento de 5000x. (C) Aspecto intragranular da HA após 90 dias de implantação em defeito ósseo proximal da tíbia direita de ovino. A alteração na morfologia intragranular está mais acentuada do que aos 60 dias, devido à solubilização do biomaterial. Aumento de 5000x.

miscroscopia óptica, foi observado que este foi o biomaterial implantado mais rapidamente absorvido. A qualidade do tecido ósseo formado foi considerada muito boa.

0 composto bifásico HA/TCP - $\beta(60 / 40)$ apresentou bom desempenho de mineralização e de formação óssea. Apresentou solubilidade intermediária entre a HA e o TCP- $\beta$, tendo absorção mais lenta do que este último mas mais rápida do que a hidroxiapatita. Aos 60 dias, pode-se observar neste grupo uma boa osteointegração, bem como formação de tecido ósseo de excelente qualidade. Aos 90 dias, observou-se um tecido ósseo maduro, colônias de osteoblastos, com presença de canais de Havers e Volkmann, além de vasos sanguíneos, essenciais ao processo de cicatrização óssea (Fig. 6). Neste momento, ainda se observou quantidade significativa de biomaterial, demonstrando que sua reabsorção não é rápida como ocorre com o TCP- $\beta$, entretanto, a qualidade do tecido ósseo formado é superior àquela observada com a hidroxiapatita isolada.

O nanocompósito $\mathrm{HA} / \mathrm{Al}_{2} \mathrm{O}_{3}$ a $5 \%$ não apresentou resultado favorável neste estudo. Observou-se uma intensa proliferação de células fagocitárias e tecido fibroso no lugar do tecido ósseo formado nos outros biomateriais estudados. Os grânulos do biomaterial implantado foram envolvidos por tecido fibroso e pode-se observar a proliferação de células fagocitárias (macrófagos) ao seu redor após 60 dias de implantação (Fig. 7). Aos 90 dias não se observou uma alteração marcante no cenário da implantação, exceto pela maior quantidade de células de linhagem fagocitária (Fig. 8). Não ocorreu redução na presença de biomaterial, contudo, observou-se, na microscopia eletrônica, inúmeros fragmentos menores dos grânulos, como possível resultado do processo de fagocitose pelas células de defesa do hospedeiro.

Os defeitos que receberam o autoenxerto apresentaram rápida osteointegração ao osso cortical adjacente, sendo difícil, já aos 60 dias, identificar a região de interface entre o fragmento transplantado e o osso remanescente. No grupo 90 dias, a interface entre fragmento ósseo enxertado e osso cortical não pode ser localizada.

\section{DISCUSSÃO}

Diversos estudos relacionados à ortopedia têm sido realizados utilizando-se ovinos como modelo experimental, devido ao seu tamanho apropriado, rusticidade e docilidade, facilitando o procedimento cirúrgico, manejo e avaliação pós-operatória (Willie et al. 2004, Shelton et al. 2011). Por serem animais de produção, a eutanásia ao final do experimento não se mostra um impasse mediante os comitês de ética e bem-estar animal, desde que seja respeitada a Resolução do CFMV n¹000/2012, de 11 de maio de 2012 para a realização do procedimento.

Para a implantação dos biomateriais analisados, foi necessária a criação de três defeitos ósseos com $6 \mathrm{~mm}$ de diâmetro. A escolha pela tíbia foi devido ao fato de esta ser um osso longo e de fácil acesso, comumente utilizado para experimentação de procedimentos ortopédicos em ovinos (Dias et al. 2007, Silva 2011, Fernandes et al. 2014), bem como em coelhos (Freitas et al. 2013, Moreira et al. 2014).

A pesquisa por substitutos ósseos e a busca por técnicas capazes de substituir o autoenxerto é contínua dentro da ortopedia. Fernandes et al. (2014), investigaram os efeitos da adição de células osteoprogenitoras em aloenxertos (fragmentos ósseos obtidos de animais diferentes dentro da mesma espécie) conservados em glicerina $98 \%$, e observaram uma rápida reconstrução óssea, estrutural e morfológica, principalmente pela alta capacidade osteoindutora destas células. Esta se mostrou uma importante ferramenta na correção de grandes defeitos ósseos.

Dada a vasta gama de biomateriais disponíveis, é corrente o uso de substitutos sintéticos, capazes de corrigir uma grande perda de tecido ósseo. A utilização de polimetilmetacrilato, ou mesmo metacrilato, associado à matriz óssea mineralizada heteróloga fragmentada (MOMHF) para preenchimento de defeito ósseo induzido experimentalmente em tíbia de coelhos, se mostrou bastante satisfatório no que diz respeito ao grau de biocompatibilidade; os resultados foram promissores e os autores sugerem, inclusive, que seu uso poderia ser empregado em espécies rotineiramente atendidas na rotina clínica-cirúrgica veterinária, como cães e gatos (Freitas et al. 2013, Moreira et al. 


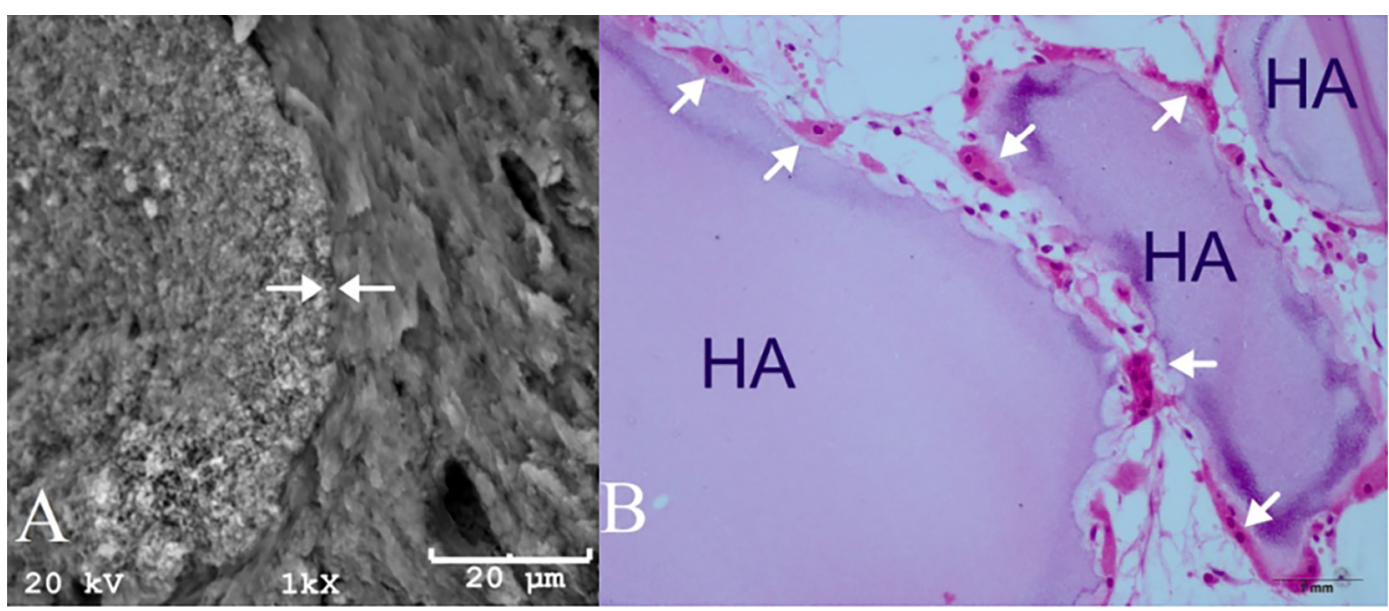

Fig.4. (A) Região de interface (setas brancas) entre biomaterial implantado (hidroxiapatita - lado esquerdo) e tecido ósseo adjacente (lado direito). Imagem do grupo de 90 dias. Aumento de 100x. (B) Imagem de microscopia óptica de um implante de hidroxiapatita em um animal do grupo de 90 dias. Há presença abundante de células de osteoclastos (setas brancas) indicando processo ativo de reparação e neoformação óssea. HE, obj.40x.

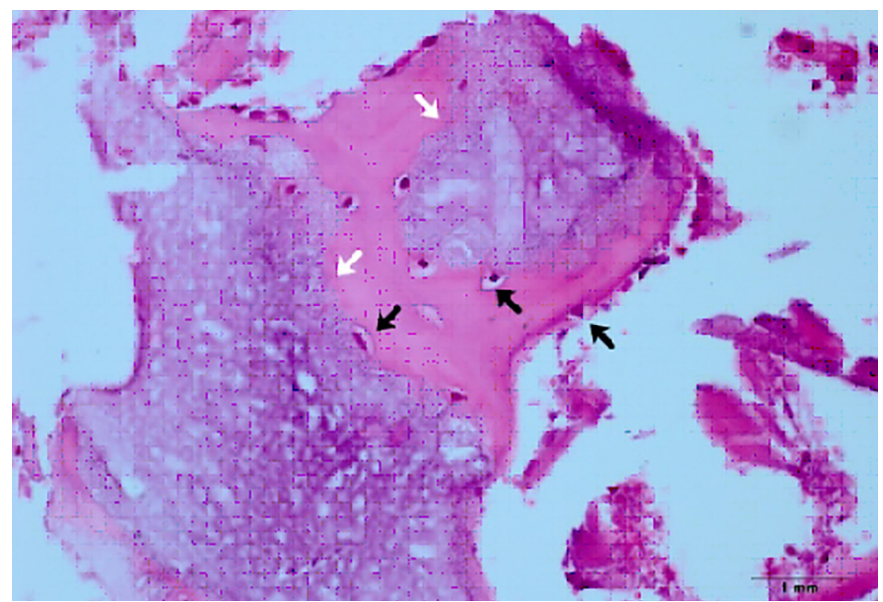

Fig.5. Imagem de microscopia óptica demonstrando formação óssea, com preenchimento de lacunas osteocíticas (setas pretas), no interior de um grânulo (setas brancas) de TCP- $\beta$ implantado em defeito ósseo distal da tíbia direita de ovino. Grupo 60 dias. HE, obj.4x.

2014). No presente estudo, foram avaliados biomateriais sintéticos com a finalidade de reparo ósseo, constituídos essencialmente por fosfatos de cálcio.

Com o intuito de acompanhar o processo de cicatrização, avaliar evidências de reação periosteal, fraturas, ou qualquer complicação capaz de comprometer o estudo, foram obtidas radiografias no pós-operatório imediato, e após 30,60 e 90 dias. Este método de avaliação se mostrou eficaz como controle, embora não tenha capacidade de diferenciar o comportamento in vivo dos diferentes biomateriais.

A hidroxiapatita é o constituinte mineral natural encontrado no osso representando de 30 a $70 \%$ da massa dos ossos e dentes (Costa et al. 2009). Os biomateriais empregados neste estudo foram obtidos pelo método de síntese via úmida, e foi demonstrado por Fulmer, Martin \& Brown (1992), que a hidroxiapatita obtida por este método pos- sui características similares às do tecido ósseo e dentário, diferentemente da hidroxiapatita sintetizada à altas temperaturas. Aos 60 dias, a HA demonstrou moderado preenchimento de lacunas osteocíticas e neoformação de tecido ósseo, e leve presença de osteoclastos e formação de tecido mieloide, indicando boa osteoindução e boa capacidade osteorregenerativa. Não foi observada deposição de fibras colágenas ou presença de infiltrado inflamatório, demonstrando claramente sua biocompatibilidade. Aos 90 dias estes resultados se mostraram mais evidentes, apresentando acentuada neoformação de tecido ósseo, com evidente preenchimento de lacunas osteocíticas, diferindo dos resultados observados por Cho, Chung \& Rhee (2011). Estes autores relataram ter observado deposição de tecido fibroso sobre os grânulos do biomaterial, lenta reabsorção pelo organismo e baixa capacidade de formação óssea, o que não corresponde aos resultados obtidos no presente estudo, que demonstrou uma boa capacidade osteoindutiva e osteocondutiva, além de não ser notado nenhum sinal de rejeição tecidual com deposição de tecido fibroso. Esta divergência pode estar associada à diferença entre os tamanhos dos grânulos, que no estudo de Cho, Chung \& Rhee (2011), variavam entre 212 a $1000 \mu \mathrm{m}$, e no atual se restringiam a uma faixa entre 200 e $500 \mu \mathrm{m}$, com presença significativa de microporosidades.

Estudos in vitro e in vivo demonstraram que fosfatos de cálcio porosos nanoestruturados apresentam maior bioatividade, especialmente maior osteoindutividade do que os convencionais, sugerindo que quanto menores forem os grânulos e mais porosidades tiverem, melhor será sua atividade na neoformação óssea (Hong et al. 2010).

0 tricálcio fosfato - $\beta$ demonstrou, aos 60 dias, uma acentuada neoformação óssea, e preenchimento de lacunas osteocíticas, além de uma leve presença de osteoclastos e formação de tecido mieloide. Isso demonstra que sua osteoindução não é tão acentuada quanto à da hidroxiapatita, entretanto, possivelmente devido à sua rápida solubilização e consequente liberação de íons cálcio e fosfato, ocorre 


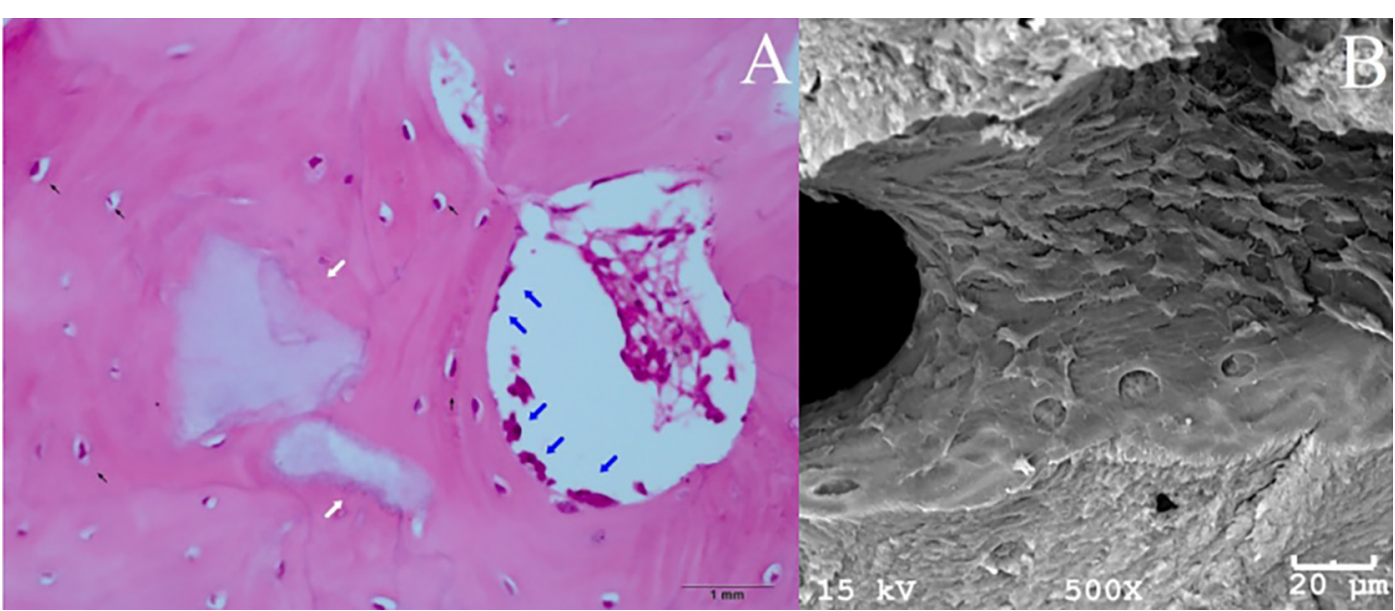

Fig.6. (A) Imagem de microscopia óptica de um ovino do grupo de 90 dias, demonstrando presença de HA/TCP- $\beta$ (60/40) remanescente (setas brancas), fortemente entremeado ao tecido ósseo neoformado. Há presença de inúmeros osteócitos (setas pretas) e osteoblastos (setas azuis), indicando tecido ósseo jovem em processo contínuo de osteogênese. HE, obj.4x. (B) Imagem de microscopia eletrônica de varredura, demonstrando uma superfície óssea rica em osteoblastos, em região implantada com HA/TCP- $\beta$ (60/40) (defeito ósseo proximal em tíbia esquerda de ovino). Grupo de 90 dias. Aumento de $500 x$.

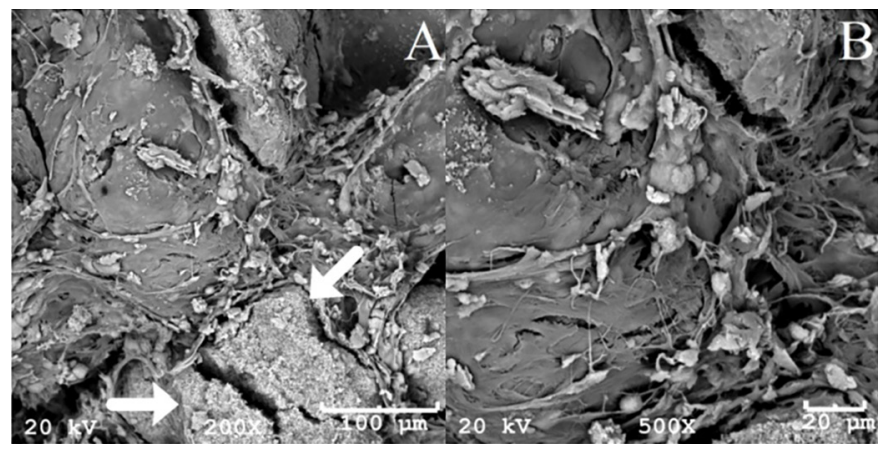

Fig.7. (A) Grânulos do biomaterial $\mathrm{HA} / \mathrm{Al}_{2} \mathrm{O}_{3}$ a $5 \%$ (setas brancas) implantados em defeito ósseo distal da tíbia esquerda de ovino, envolvidos por tecido fibrocolagenoso. Aumento de 200x. (B) Tecido fibroso desorganizado circundando o biomaterial $\mathrm{HA} / \mathrm{Al}_{2} \mathrm{O}_{3}$ a $5 \%$ implantado em ovino. Aumento de 500x). Grupo 60 dias.

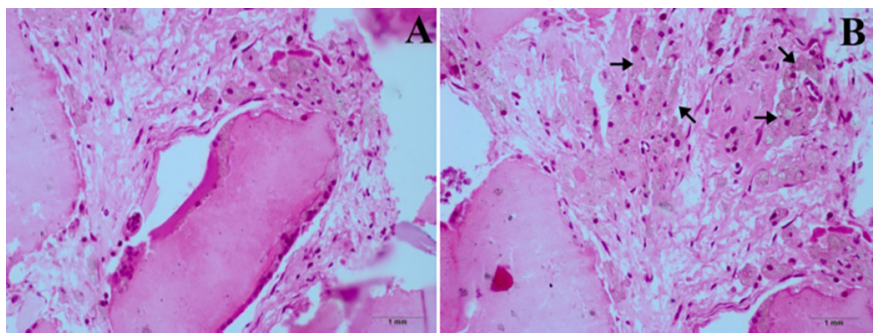

Fig.8. (A) Imagens histológicas de grânulos de HA/Al2O3 a 5\% implantados em defeito ósseo distal esquerdo em ovinos, circundados por macrófagos. Há tecido fibroso adjacente às células (H\&E aumento 40x). (B) Observa-se intensa formação de tecido fibroso e macrófagos repletos por biomaterial fagocitado, com pigmentação escura no citoplasma celular (setas pretas). Grupo de 90 dias, HE, obj.4x.

reparação óssea de modo rápido e significativo. Aos 90 dias, a formação já foi considerada muito acentuada. Apesar de apresentar uma leve deposição de fibras colágenas aos 90 dias, não se sugere que o TCP- $\beta$ seja menos biocompatível.
Presume-se que esta deposição ocorra em função da alta porosidade do biomaterial, que permite uma acentuada agregação de prolongamentos celulares e proteínas diversas no interior do grânulo, como etapa normal do processo de cicatrização. Estudos recentes, que avaliaram o uso do tricálcio fosfato - $\beta$ como substituto ósseo revelaram melhores resultados para formação óssea e na velocidade de degradação, do que aqueles obtidos com a hidroxiapatita (Perera et al. 2010, Ye et al. 2012), corroborando com os resultados obtidos no presente estudo.

Kondo et al. (2006), implantaram blocos de TCP- $\beta$ no músculo paravertebral de cadelas da raça Beagle, e observaram formação óssea após 56 dias em quatro de cinco animais, o que condiz com o resultado da presente pesquisa, em que foi observada boa formação de tecido ósseo já no grupo de 60 dias.

A porosidade do TCP- $\beta$ varia entre 46,07 e $54,44 \%$. Densidade e porosidade são características inversamente relacionadas, ou seja, quando a porosidade aumenta, a densidade, normalmente, diminui, e vice-versa (Santos et al. 2012). A sua alta porosidade explica a formação de tecido ósseo no interior dos grânulos de TCP- $\beta$, como foi observado no presente estudo, inclusive alterando significativamente sua morfologia interna. Além da composição química, a estrutura porosa facilita o processo de reparação óssea por um implante ósseo (Hing et al. 1999). A porosidade é, em geral, baseada na presença de poros abertos, que estão relacionados à propriedades como permeabilidade e área de superfície da estrutura porosa (Kim et al. 2012). No presente estudo foi observada leve deposição de fibras colágenas em um animal do grupo de 90 dias, o que não demonstra um sinal de rejeição ao implante, devido à presença de células de linhagem osteoblástica e a intensa formação de tecido ósseo com este biomaterial. Estudos in vitro demonstraram adesão e proliferação celular ao redor dos implantes de TCP- $\beta$ em 24, 48 e 72 horas, além de verificar ausência de citotoxicidade aguda (Santos et al. 2012). 
A alta absorção do TCP- $\beta$, com liberação rápida de íons cálcio e fosfato quando em meio fisiológico, entretanto, não se mostra somente benéfica. Esta rápida dissolução reduz drasticamente a área de superfície disponível para proliferação de células ósseas e, portanto, limita sua aplicação clínica (Yamada et al. 1997). Daculsi et al. (1990), já descreviam a utilização de compostos bifásicos com $60 \%$ de hidroxiapatita e $40 \%$ de tricálcio fosfato- $\beta$ para uso clínico, associando boa solubilidade com maior resistência mecânica.

A composição bifásica apresentou moderado preenchimento de lacunas osteocíticas e moderada formação de tecido mieloide e neoformação óssea aos 60 dias. Não houve deposição de fibras colágenas ou infiltrado inflamatório durante o período deste estudo, possivelmente porque sua porosidade é menor do que aquela observada no TCP- $\beta$. A capacidade osteorregenerativa e osteoindutiva se mostrou acentuada aos 90 dias, sugerindo que apresenta boa bioatividade, embora com solubilidade mais lenta em relação ao TCP- $\beta$, o que pode ser uma boa alternativa, segundo Yamada et al. (1997) e Daculsi et al. (1990).

Foi observada, neste estudo, uma lenta reabsorção deste material quando comparado ao TCP- $\beta$ isolado, porém uma rápida formação de tecido ósseo de boa qualidade. A força mecânica fornecida pela hidroxiapatita pode ser benéfica a longo prazo, dependendo da aplicação a que este material esteja destinado. Até o presente momento, o composto bifásico $60 \%$ HA/40\% TCP- $\beta$, é o melhor material conhecido, pois sua capacidade alia a rápida solubilidade do TCP- $\beta$ à superior biocompatibilidade da HA (Kim et al. 2012).

Huang et al. (2010), compararam a implantação de uma apresentação comercial do composto bifásico HA/TCP- $\beta$ 60:40 com um grupo controle (sem preenchimento) em defeitos criados no osso alveolar de cães da raça Beagle e os resultados obtidos demonstraram uma taxa de neoformação óssea de 49,5\% com o composto bifásico após 5 semanas de implantação, enquanto nenhuma formação foi observada no grupo controle no mesmo período; oito semanas após a implantação, havia $68,1 \%$ de formação óssea com o biomaterial e 18,9\% no grupo controle e, após 10 semanas, observou-se uma formação óssea de $74,5 \%$ e $40,2 \%$, com o HA/TCP- $\beta$ 60:40 e o grupo controle, respectivamente. 0 grupo controle, no estudo corrente, apresentou o melhor resultado, como era esperado, mas diferiu dos achados de Huang et al. (2010), pois neste caso houve preenchimento do defeito criado com um fragmento ósseo do próprio paciente (autoenxerto). Este resultado já era esperado pelos autores, visto que esta técnica ainda é considerada padrão-ouro na substituição óssea; o objetivo, portanto, foi encontrar um biomaterial capaz de substituir este método, dadas as suas desvantagens, como necessidade de procedimento cirúrgico adicional e maior risco de morbidade da área doadora. A remodelação óssea foi muito rápida neste grupo, visto que já aos 60 dias foi praticamente impossível identificar as linhas de interface entre osso cortical e fragmento implantado.

Compostos de hidroxiapatita e outras cerâmicas, tais como alumina e zircônia, podem combinar a biocompatibilidade da hidroxiapatita à vantagens mecânicas dos materiais complementares (Başar et al. 2011). Embora a alumina seja bioinerte e conhecida por sua força química e mecânica, ela não forma ligações bioquímicas com o tecido (Yelten, Yilmaz \& Oktar 2012). No presente estudo, porém, os resultados encontrados com esta cerâmica não foram satisfatórios.

Yelten, Yilmaz \& Oktar (2012), relataram que a $\alpha$-alumina, a única fase estável deste material, é obtida a 1250-1300ㄷ․ Em temperaturas mais baixas, são produzidas outras fases da alumina, tais como $\gamma-\mathrm{Al}_{2} \mathrm{O}_{3}, \delta-\mathrm{Al}_{2} \mathrm{O}_{3}$, $\theta-\mathrm{Al}_{2} \mathrm{O}_{3}$, as quais são amorfas e instáveis. 0 composto HA/ $\mathrm{Al}_{2} \mathrm{O}_{3}-\alpha$ utilizado foi sinterizado à $1100^{\circ} \mathrm{C}$, e sabe-se que estes compostos podem apresentar tensões residuais termoelásticas na interface de grãos quando sinterizados a temperaturas abaixo de $1200^{\circ} \mathrm{C}$. Essas tensões são geradas durante o processo de sinterização e resfriamento do biomaterial, podendo levar ao surgimento de microtrincas ou mesmo à degradação total do biomaterial (Barralet, Best \& Bonfield 2000, Bellini 2007, Corrêa 2013). As tensões residuais termoelásticas de origem térmica ou mecânica conduzem a uma excitação atômica na superfície dos grãos, o que pode inibir a proliferação celular na superfície do material, além de desencadear um processo de necrose inicial, posteriormente favorecendo a deposição de tecido fibroso na interface do biomaterial (Santos 2009, Corrêa 2013). A consequência disso pode ter sido os efeitos evidenciados no presente estudo, com reação do organismo a um corpo estranho e tentativa das células de defesa em remover o biomaterial, o que foi presenciado em todos os animais avaliados, com menor intensidade no grupo de 60 dias e mais acentuado aos 90 dias, por meio da deposição de fibras colágenas e infiltrado inflamatório, que variou de moderado a acentuado entre os tempos avaliados. Başar et al. (2011), investigaram a biocompatibilidade in vitro de um nanocompósito de hidroxiapatita e alumina associados ao fluoreto de cálcio $\left(\mathrm{CaF}_{2}\right)$, sinterizados a $1100^{\circ} \mathrm{C}$, e detectaram uma redução no volume de células do cultivo, quando comparado àquele obtido com a HA pura, sugerindo mais estudos antes de sua aplicação biomédica.

Estes resultados não são suficientes para afirmar que a alumina não se comporta bem in vivo, dada à vasta literatura que a recomenda. Santos et al. (2009), avaliaram as propriedades mecânicas e a citotoxicidade de biocerâmicas à base de zircônia enriquecida com alumina e verificaram que o material não é citotóxico e apresenta grande potencial para aplicação como implantes. Sugere-se, portanto, novos estudos com alteração no método de produção deste composto, com o intuito de, realmente, avaliar o comportamento da $\mathrm{HA} / \mathrm{Al}_{2} \mathrm{O}_{3}$ in vivo.

\section{CONCLUSÕES}

Conclui-se que a hidroxiapatita, o tricálcio fosfato- $\beta$ e a associação HA/TCP- $\beta(60 / 40)$ apresentam boa capacidade de reparação óssea, com propriedades ostoindutivas e osteocondutivas, podendo ser utilizados como substitutos ósseos.

Por aliar as características encontradas na $\mathrm{HA}$ e no TCP- $\beta$, a associação HA/TCP- $\beta(60 / 40)$ é o biomaterial mais indicado para a substituição óssea, dentre os avaliados nes- 
te estudo, apresentando velocidade de absorção intermediária em relação à HA e ao TCP- $\beta$ isolados e fornecendo ainda uma sustentação adequada ao tecido neoformado.

0 biomaterial $\mathrm{HA} / \mathrm{Al}_{2} \mathrm{O}_{3} 5 \%$ se mostrou ineficaz, provocando reação inflamatória exacerbada, nenhum grau de absorção e nenhuma capacidade osteoindutiva ou osteocondutiva. Sugere-se novas pesquisas acerca deste biomaterial para melhores esclarecimentos.

\section{REFERÊNCIAS}

Barralet J.E., Best S.M. \& Bonfield W. 2000. Effect of sintering parameters on the density and microstructure of carbonate hydroxyapatite. J. Mater. Sci. Mater. Med. 11:719-724.

Başar B., Tezcaner A., Keskin D. \& Evis Z. 2011. Synthesis, phase transitions and cellular biocompatibility of nanophase alumina-hydroxyapatite composites. Adv. Appl. Ceram. 110:238-243.

Bellini 0.J. 2007. Síntese e caracterização de uma matriz óssea de fosfato de cálcio e nanocompósitos fosfato de cálcio/SiO2-alfa para substituição e regeneração óssea. Dissertação de Mestrado, Centro de Ciências Tecnológicas, Universidade do Estado de Santa Catarina, Joinville. 97p.

Burstein F.D., Cohen S.R., Hudgins R. \& Boydston W. 1997. The use of porous granular hydroxyapatite in secondary orbitocranial reconstruction. Plast. Reconstr. Surg. 100:869-874.

Cho J.S., Chung C. \& Rhee S. 2011. Bioactivity and Osteoconductivity of Biphasic Calcium Phosphates. Bioceram. Dev. Appl. 1:1-3.

Chow L.C. 2009. Next generation calcium phosphate-based biomaterials. Dent. Mater. J. 28:1-10.

Corrêa P. 2013. Síntese e caracterização de nanocompósitos $\mathrm{HA} / \mathrm{Al}_{2} \mathrm{O}_{3}-\alpha$ sol-gel para aplicações na reconstrução óssea. Dissertação de Mestrado, Centro de Ciências Tecnológicas, Universidade do Estado de Santa Catarina, Joinville. 106p.

Costa A.C.F.M., Lima M.G., Lima L.H.M.A., Cordeiro V.V., Viana K.M.S., Souza C.V. \& Lira H.L. 2009. Hidroxiapatita: obtenção, caracterização e aplicações. Rev. Eletrônica Mater. Processos 4:29-38.

Daculsi G. 1998. Biphasic Calcium Phosphate Concept Applied to Artificial Bone, Implant Coating and Injectable Bone Substitute. Biomaterials 19:1473-1478.

Daculsi G., Passuti N., Martin S., Deudon C., Legeros R.Z. \& Raher S. 1990. Macroporous calcium phosphate ceramic for long bone surgery in humans and dogs. Clinical and histological study. J. Biomed. Mater. Res. 24:379-396.

Dalmônico G.M.L. 2011. Síntese e caracterização de fosfato de cálcio e hidroxiapatita: elaboração de composições bifásicas HA/TCP- $\beta$ para aplicações biomédicas. Dissertação de Mestrado, Centro de Ciências Tecnológicas, Universidade do Estado de Santa Catarina, Joinville. 101p.

Dias M.I., Lourenço P., Rodrigues A., Azevedo J., Viegas C., Ferreira A. \& Cabrita A.S. 2007. 0 efeito da quantidade do enxerto de osso esponjoso autólogo utilizado na regeneração óssea num modelo experimental de osteotomia da tíbia. Acta Med. Port. 20:37-46.

Dorozhkin S. 2007. Calcium orthophosphates. J. Mater. Sci. 42:1061-1095.

Fernandes M.B.C., Guimarães J.A.M., Casado P.L., Cavalcanti A.S., Gonçalves N.N., Ambrósio C.E., Rodrigues F., Pinto A.C.F., Miglino M.A. \& Duarte M.E.L. 2014. The effect of bone allografts combined with bone marrow stromal cells on the healing of segmental bone defects in a sheep model. BMC Vet. Res. 10:1-12.

Freitas S.H., Dória R.G.S., Mendonça F.S., Camargo L.M., Presser C.I., Santos M.D., Shimano A.C. \& Ambrósio C.E. 2013. Avaliação morfológica e por imagem radiográfica da matriz óssea mineralizada heteróloga fragmentada e metilmetacrilato, preservados em glicerina para reparação de falhas ósseas em tíbias de coelhos. Pesq. Vet. Bras. 33:765-770.

Fulmer M.T., Martin R.I. \& Brown P.W. 1992. Formation of calcium deficient hidroxyapatite at near-physiological temperature. J. Mater. Sci. Mater. Med. 3:299-305.

Hing K.A., Best S.M. \& Bonfield W. 1999. Characterization of porous hydroxyapatite. J. Mater. Sci. Mater. Med. 10:135-145.
Hong Y., Fan H., Li B., Guo B., Liu M. \& Zhang X. 2010. Fabrication, biological effects, and medical applications of calcium phosphates nanoceramics. Mater. Sci. Eng., R. 70:225-242.

Hönig J.F., Merten H.A. \& Wiltfang J. 1998. Significance of the periosteum in onlay craniofacial augmentation. J. Craniofac. Surg. 9:260-266.

Huang M., Wu H., Teng N., Peng B., Wu J., Chang W., Yang J., Chen C. \& Lee S. 2010. In vivo evaluation of poorly crystalline hydroxyapatite-based biphasic calcium phosphate bone substitutes for treating dental bony defects. J. Dent. Sci. 5:100-108.

Johnson A.L. 2008. Tratamento de fraturas específicas, p.1015-1142. In: Fossum T.W. (Ed.), Cirurgia de Pequenos Animais. 3aㅡ ed. Elsevier, São Paulo. 1606p.

Kamitakahara M., Ohtsuki C. \& Miyasaki T. 2008. Review Paper: Behavior of Ceramic Biomaterials Derived from Tricalcium Phosphate in Physiological Condition. J. Biomater. Appl. 23:197-212.

Kim T., Park Y.M., Kim D., Jin H., Shin K., Jung J.S., Park H. \& Yoon S. 2012. In situ formation of biphasic calcium phosphates and their biological performance in vivo. Ceram. Int. 38:1965-1974.

Kondo N., Ogose A., Tokunaga K., Umezu H., Arai K., Kudo N., Hoshino M., Inoue H., Irie H., Kuroda K., Mera H. \& Endo N. 2006. Osteoinduction with highly purified $\beta$-tricalcium phosphate in dog dorsal muscles and the proliferation of osteoclasts before heterotopic bone formation. Biomaterials 27:4419-4427.

Legeros R.Z. 2002. Properties of osteoconductive biomaterials: calcium phosphates. Clin. Orthop. Relat. Res. 460:81-98.

Martinez A.S. \& Walker T. 1999. Bone grafts. Vet. Clin. North Am. 29:12071209.

Mellonig J.T. 1991. Porous particulate hydroxyapatite in a human periodontal osseous defect: a case report. Int. J. Periodontics Restorative Dent. 11:217-223.

Moore W.R., Graves S.E. \& Bain G.I. 2001. Synthetic bone graft substitutes. ANZ J. Surg. 71:354-361.

Moreira R., Dória R.G.S., Camargo L.M., Santos M.D., Minto B.W., De Nardi A.B., Ambrósio C.E. \& Freitas S.H. 2014. Aspecto radiológico e macroscópico de matriz óssea mineralizada heteróloga fragmentada e polimetilmetacrilato autoclavados em falha óssea de tíbia de coelho. Pesq. Vet. Bras. 34:173-178.

Perera F.H., Martínez-Vázquez F.., Miranda P., Ortiz A.L. \& Pajares A. 2010. Clarifying the effect of sintering conditions on the microstructure and mechanical properties of $\beta$-tricalcium phosphate. Ceram. Int. 36:19291935.

Piermatei D.L. \& Johnson K.A. 2004. Approach to the proximal tibia through a medial incision, p.367-369. In: Ibid. (Eds), An Atlas of Surgical Approaches to the Bones and Joints of the Dog and Cat. 4th ed. W.B. Saunders, Philadelphia.

Prophet E.B., Mills B., Arrington J.B. \& Sobin L.H. 1992. Laboratory Methods in Histotechnology. American Registry of Pathology, Armed Forces Institute of Pathology, Washington, DC. 279p.

Rabelo Neto J.S. 2009. Hidroxiapatita sintética nanoestruturada e esmalte dental aquecidos e irradiados por laser de Er,Cr:Ysgg: caracterização por Ftir e por DRX. Dissertação de Mestrado, Instituto de Pesquisas Energéticas e Nucleares, São Paulo. 120p.

Santos C.F.L., Silva A.P., Lopes L., Pires I. \& Correia I.J. 2012. Design and production of sintered $\beta$-tricalcium phosphate 3D scaffolds for bone tissue regeneration. Mater. Sci. Eng. C. 32:1293-1298.

Santos C., Teixeira L.H.P., Daguano J.K.M.F., Rogero S.O., Strecker K. \& Elias S.N. 2009. Mechanical properties and cytotoxicity of 3Y-TZP bioceramics reinforced with $\mathrm{Al}_{2} \mathrm{O}_{3}$ particles. Ceram. Int. 35:709-718.

Santos R.B.M. 2009. Síntese e caracterização de pós nanoestruturados de fosfatos de cálcio e nanocompósitos hidroxiapatita/sílica-gel. Dissertação de Mestrado, Centro de Ciências Tecnológicas, Universidade do Estado de Santa Catarina, Joinville. 95p.

Shelton T.J., Beck J.P., Bloebaum R.D. \& Bachus K.N. 2011. Percutaneous osseointegrated prostheses for amputees: Limb compensation in a 12-month ovine model. J. Biomech. 44:2601-2606. 
Silva R.B. 2011. Desvitalização extracorpórea de autoenxerto ósseo cortical com nitrogênio líquido - estudo experimental em tíbia de ovelhas. Dissertação de Mestrado em Ciências Veterinárias, Faculdade de Veterinária, Universidade Federal do Rio Grande do Sul, Porto Alegre. 53p.

Sturm S., Zhou S., Mai Y. \& Li Q. 2010. On stiffness of scaffolds for bone tissue engineering: a numerical study. J. Biomech. 43:1738-1744.

Thomson R.C., Yaszemski M.J., Powers J.M. \& Mikos A.G. 1998. Hydroxyapatite fiber reinforced poly (alpha-hydroxy ester) foams for bone regeneration. Biomaterials 19:1935-1943.

Valiati R. 2011. Análise do efeito da laserterapia na incorporação de aloenxertos ósseos em blocos processados por congelamento profundo estudo em coelhos. Tese de Doutorado em Odontologia, Faculdade de Odontologia, Pontifícia Universidade Católica do Rio Grande do Sul, Porto Alegre. $124 \mathrm{p}$.
Willians D.F. 1987. Definitions in biomaterials. J. Polymer Sci. C, Polymer Lett. 26:381-416.

Willie B.M., Bloebaum R.D., Bireley W.R., Bachus K.N. \& Hofmann A.A. 2004. Determining relevance of a weight-bearing ovine model for bone ingrowth assessment. J. Biomed. Mater. Res. A 69A:567-576.

Yamada S., Heymann D., Bouler J.M. \& Daculsi G. 1997. Osteoclastic resorption of calcium phosphate ceramics with different hydroxyapatite/ $\beta$-tricalcium phosphate ratios. Biomaterials 18:1037-1041.

Ye X., Yin X., Yang D., Tan J. \& Liu G. 2012. Ectopic bone regeneration by human bone marrow mononucleated cells, undifferentiated and osteogenically differentiated bone marrow mesenchymal stem cells in beta-tricalcium phosphate scaffolds. Tissue Eng. C. Methods 18:545-556.

Yelten A., Yilmaz S. \& Oktar F.N. 2012. Sol-gel derived alumina-hydroxyapatite-tricalcium phosphate porous composite powders. Ceram. Int. 38:2659-2665. 